\title{
Development of a control system for a ballast cleaning machine using GNSS
}

\author{
Vladimir Shcherbakov ${ }^{1, *}$, Ivan Buntsev ${ }^{1}$, and Olga Kovaleva ${ }^{1}$ \\ ${ }^{1}$ Siberian Transport University (STU), 191 Dusi Kovalchuk st., Novosibirsk, 630049 Russia
}

\begin{abstract}
Monitoring the geometric parameters of cutting and cleaning ballast during reconstruction and overhaul works is one of the most important tasks of ensuring high quality repair work. The paper describes a new type of automated control system to control the cutting process and the cleaning of ballast performed at major overhaul and reconstruction. This automated control system uses the data of a multisystem GNSS receiver, base reference stations and spring-return mechanisms for installing antennas on the working body of the track machine (bar chain). Nowadays, gravel-cleaning machines have installed standard work quality control systems (depth of ballast cut and lateral slope), and other measuring control tools are also used. The disadvantages of existing technologies and instrumental testing are considered. The modern automatic control systems of various types developed by SGUPS and based on the use of global navigation systems are presented. Detailed schemes of working elements of ACS installed on the ballast cleaning machine (BCM) are presented. Algorithms to determine the depth and cross slope of the ballast cutting and control of these values are considered. The use and effectiveness of this type of ACS providing the required accuracy of work and continuous monitoring of the main quantities are substantiated.
\end{abstract}

\section{Introduction}

Nowadays, standard control systems are based on relative methods [1], which allow measuring the depth of cut and transverse slopes by deepening the bar chain relative to the rail head. This approach (attachment to rail threads) does not provide high quality work and execution of design solutions, since, from the time of the beginning of surveys to repair of the track, the elevations of rail threads vary up to $5 \mathrm{~cm} \mathrm{[2].} \mathrm{In} \mathrm{addition,} \mathrm{before} \mathrm{starting} \mathrm{the}$ works, the rail-sleeper grate is raised by $1-10 \mathrm{~cm}$ relative to the existing height position using special track machines in accordance with the technology of work in order to ensure stable operation of BCM. This leads to errors in determining the depth of cut and slopes at values that do not meet regulatory requirements. The control systems, which are based on geodetic methods, are not affected by the given factors, they are used as a means of monitoring the quality of work of $\mathrm{BCM}$. Laser plane builders, tachometers with

\footnotetext{
* Corresponding author: vvs@stu.ru
} 
benchmarks [3], levels, patterns are used, but the problem is that this work is laborious and taking into account the fact that cutting is performed continuously for 20-60 hours on a closed stretch with the change of crews of drivers, surveyors must also have several teams to ensure $100 \%$ control. Moreover, in the state of operational control, there is only one surveyor or road foreman.

\section{Research Methods}

Siberian Transport University (SGUPS) has developed several different types of instruments for monitoring the process of cutting and cleaning ballast. The determination of the coordinates and geometric parameters of the rail track for these systems is based on the use of GNSS [4, 5, 6]. Automated control system ACS which is based on GNSS and sensors of the angular position of the working units (conveyor) control and automatic control system (ACS) for construction processes based on the hydrostatic excess control system of working bodies with respect to the satellite antenna phase centers [7,8].

These systems were implemented at West-Siberian Railway, and in 2016, three automatic control system were installed on RM-2002 and BCM-1200 vehicles. Experience has shown that systems have a complex mechanism of settings and calibrations of sensors, and most importantly, these settings and calibrations must be monitored periodically [9, 10]. Based on the experience of operating the automatic control systems in 2015-2017, the automatic control system was developed significantly differing in a significant reduction in the level of laboriousness during settings and calibration, as well as in increased measurement accuracy and data reliability. The accuracy of the definitions is within the tolerances [11].

The essence of the development is to compare current and design coordinates, including elevations of the lower working part of the bar chain using a multisystem GNSS positioning receiver, the antennas of which are mounted with the ability to move vertically on rods equipped with spring-return mechanisms that are rigidly connected to the ballast cleaning machine frame. Spring-return mechanisms provide the tension of the cables connecting the rods to the plows of the ballast-cleaning machine, regardless of the direction of movement of the rod and, accordingly, the antenna rigidly connected to it, up or down. This leads to a high-precision determination of the elevations of the plows of a ballast-cleaning machine at a satellite antenna height of up to six meters relatively to the bar chain intended for cutting the contaminated ballast (working body of a ballast-cleaning machine).

The ballast cleaner equipped with a new type of automatic control system is presented below. Figures 1a, 1b, 1c shows a general view of a ballast-cleaning machine equipped with automatic control system, figure 2 shows the principle of operation of automatic control systems based on GNSS, figure 3 shows the kinematic diagram of the ballast-cleaning machine equipped with automatic control system, and figure 4 shows a structural diagram that includes the main blocks of automatic control systems. 


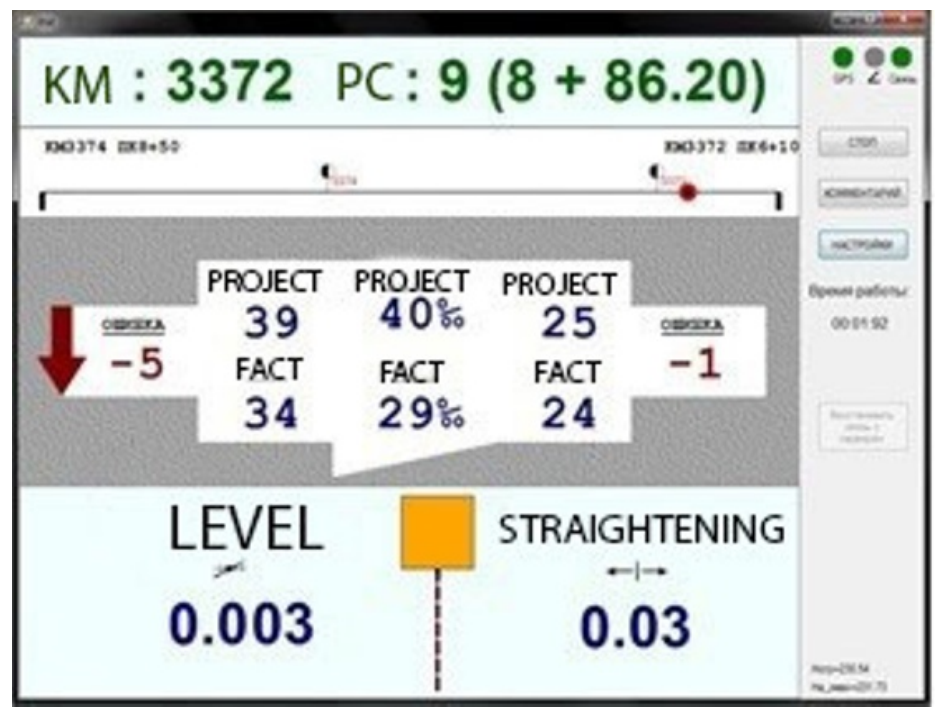

Fig. 1. General view of the ballast cleaner equipped with automatic control system based on GNSS, the operator window (a).

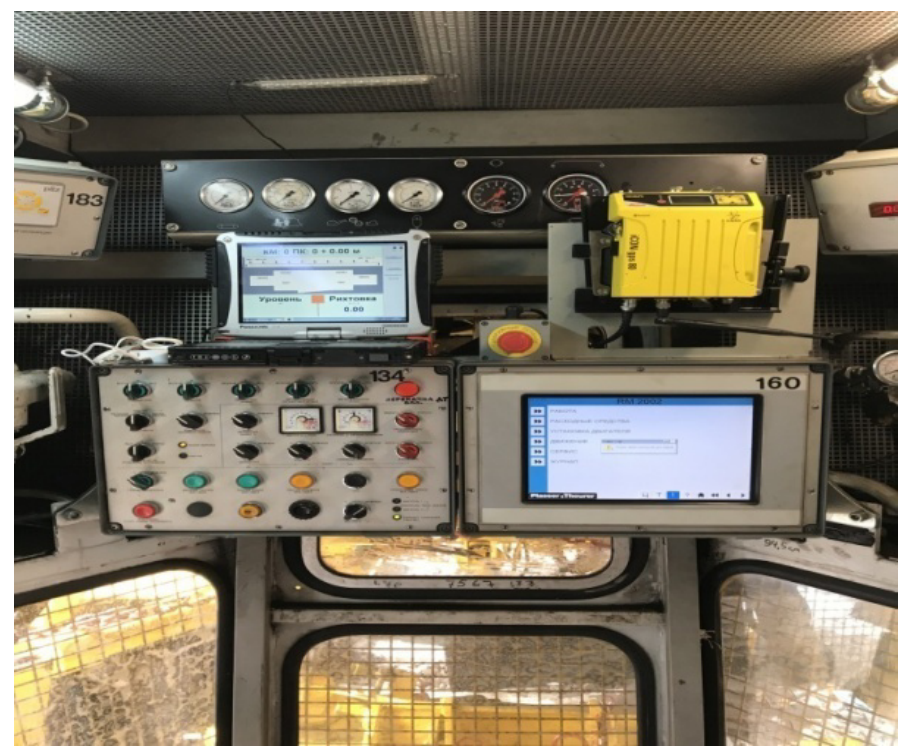

Fig. 2. General view of the ballast cleaner equipped with automatic control system based on GNSS, the operator window (b). 


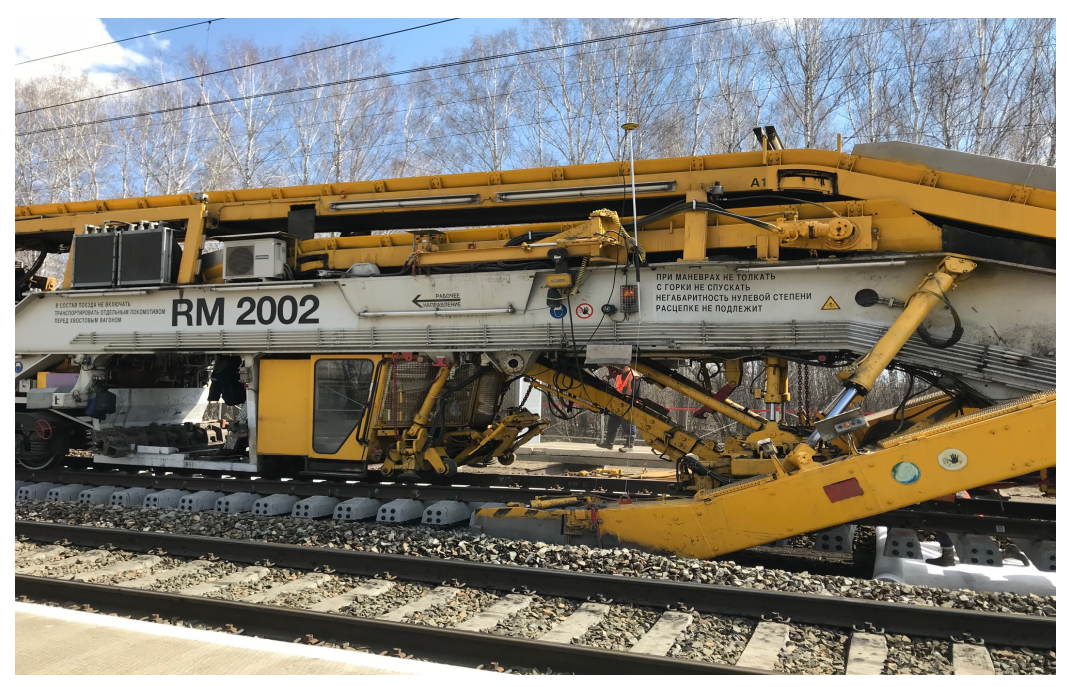

Fig. 3. General view of the ballast cleaner equipped with automatic control system based on GNSS, the operator window (c).

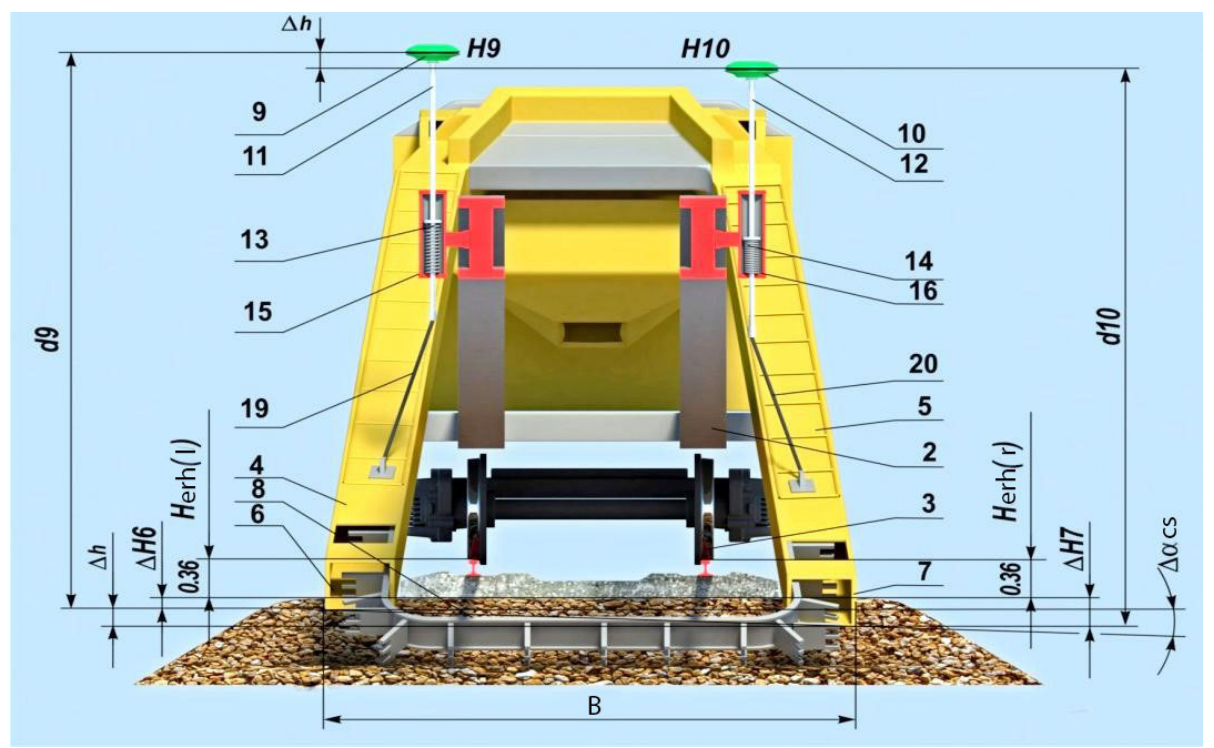

Fig. 4. Kinematic diagram of ACS based on GNSS of a ballast cleaner. 


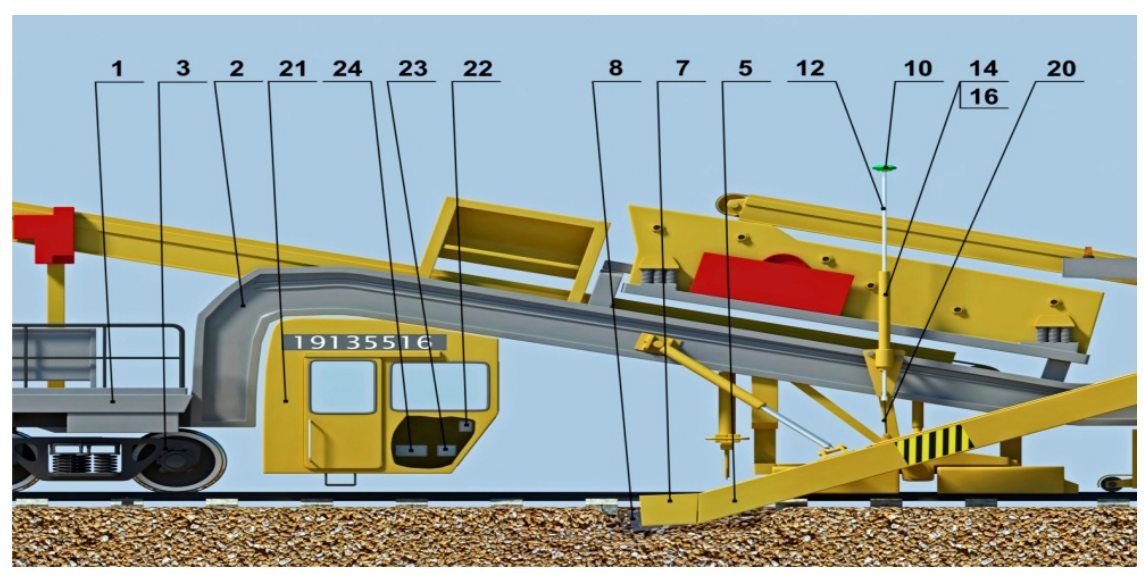

Fig. 5. Kinematic diagram of a ballast cleaner equipped with ACS based on GNSS.

Ballast cleaning machine

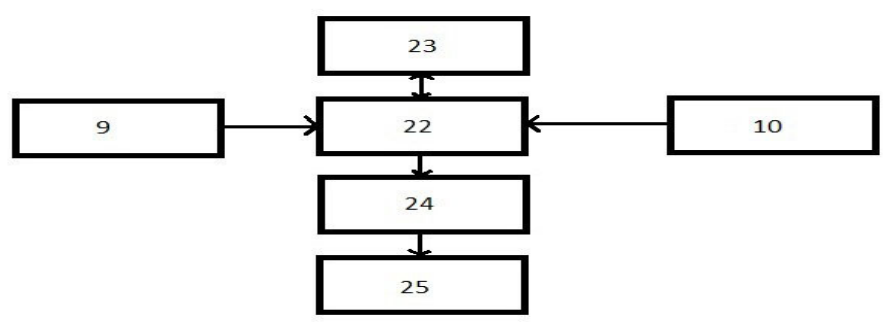

Fig. 6. Block diagram of a ballast cleaner equipped with ACS based on GNSS.

The ballast cleaning machine 1 [2] contains a frame 2 supported by running gears 3 . Conveyors 4 and 5 with plows 6 and 7 are fixed on the frame 2, and a bar chain 8 is fixed between them. Above the plows 6,7 are the first and second satellite antennas 9, 10, respectively, mounted on the rods 11,12 . The rods 11,12 in the middle part are equipped with spring-return mechanisms 13,14 . Spring-return mechanisms are rigidly fixed to the frame 2 of the crushing machine, the upper ends of the springs are fixed to the corresponding rod 11, 12, and the opposite ones - rest against the lower end of the corresponding body 15,16 .

Each of these spring-return mechanisms 13, 14 is rigidly fixed, for example, using magnets or clamps (not shown) on the frame 2. The rods 11 and 12 in their lower part are connected by flexible cables 19, 20 with the corresponding plows 6,7 of the ballastcleaning machine. Flexible cables 19, 20 at the ends have special clamps for attaching to plows 6,7 and rods 11,12 .

Antennas 9 and 10 are connected to a satellite receiver 22 located in the working cabin 21 of the ballast-cleaning machine 1 , also connected to a modem 23 , through which it is connected to satellite reference networks or temporary base stations (not shown).

The output of the satellite receiver 22 is connected to a control unit 24 , representing a computer, which performs calculations and generates a corresponding control signal supplied to the control device 25 of the drive of conveyors 4 and 5 with plows 6 and 7 .

As the satellite receiver 22 GNSS the satellite receiver of geodesic type - Leica Icon 80 - is used. 
The length of the compression coil springs 17, 18 should correspond to the possible range of movement along the height of satellite antennas 9, 10, the value of which should provide a given (known) range of ballast cutting, and, as a rule, is $0.5-1 \mathrm{~m}$.

Ballast cleaning machine, operates as follows.

Before the start of works, to the control unit 24 (laptop computer) the project data (digital project) of the appropriate structure and formats are exported, including design values of the depth of cut, longitudinal and transverse slopes, and project coordinates (X, Y, H) for linking the bar chain 8 .

In the process, satellite antennas 9 and 10 receive signals from GNSS navigation satellites and transmit data through communication channels to satellite receiver 22, which is also connected to a modem 23 that receives differential corrections from base stations of the reference network or other differential correction systems with known altitude marks.

To calculate the current coordinates $\mathrm{X}, \mathrm{Y}, \mathrm{H}$ of the location of the bar chain 8 , the satellite receiver 22 processes the data from antennas 9, 10 and the modem 23 .

During the movement of the BCM 1 along the cleaned rail track with a change in the depth of the crushed stone, the altitude of the plows 6 and 7 changes, rigidly connected by ropes 19, 20 with antennas 9 and 10 mounted, respectively, on the rods 11 and 12 . Moreover, the indicated first and second antennas 9, 10 synchronously with the change in the altitude position of the plows 6 and 7 and, accordingly, the bar chain 8 are moved along the height by the values of H6 and H7 (Figure 3). When the plows 6 and 7 are raised up, the springs 17,18 of the spring-return mechanisms 15, 16 are compressed, and, conversely, when the plows 6 and 7 are deepened, the springs 17, 18 are stretched, thus ensuring the tension of the cables 19, 20 regardless of plows 6 and 7 movement up or down.

This ensures that the displacement values of the antennas 9 and 10 correspond to the same amount by which the plows 6,7 move along the height, regardless of the vertical displacements of the position of the frame 2 in the range of spring lengths 13, 14, which allows determining the depth of cut with higher accuracy.

This solution significantly simplifies the use of servo drives, step motors with a feedback system to solve the problem of controlling the altitude of the working bodies of construction track machines.

To recalculate the elevations from the antennas 9,10 to the bottom of the bar chain 8 , preliminary, before starting the works, the heights $\mathrm{d} 9$ and d 10 of the antennas 9,10 to the bottom of the bar chain 8 are measured, the values of which are exported to the control unit 24 (Fig. 4).

\section{Research Results}

When moving the BCM [7] along the rail track, the current coordinates from the antennas 9 and 10 simultaneously with the differential corrections from the reference network using the modem 23, arrive at the receiver 22, from which the current location coordinates (bar chain) respectively enter the control unit 24 . In the control unit 24 , the necessary cutting depths are calculated for each of the plows 6 and 7 of the conveyors 4 and 5 in accordance with formulas (1) and (2):

$$
\begin{gathered}
\Delta \mathrm{H}_{6}=(\mathrm{H} \operatorname{erh}(\mathrm{l}),-0.36)-\left(\mathrm{H}_{9}-\mathrm{d}_{9}\right) \\
\Delta \mathrm{H}_{7}=(\mathrm{H} \operatorname{erh}(\mathrm{r}),-0.36)-\left(\mathrm{H}_{10}-\mathrm{d}_{10}\right)
\end{gathered}
$$

where $\Delta \mathrm{H}_{6}, \Delta \mathrm{H}_{7}$ - plows 6,7 cutting depth respectively;

$\mathrm{H}_{9}, \mathrm{H}_{10}$ - antennas' elevations 9,10 , respectively;

$\mathrm{d}_{9}$ and $\mathrm{d}_{10^{-}}$height of the antennas 9,10 , respectively, relative to the bottom bar chain 8 ; 
Herh(r), Herh(l) - the elevations of the existing railheads, respectively, of the right and left rail lines;

0.36 - the height of the railhead relatively to the bottom of the rail-sleeper grid.

The values of the project cutting depth, respectively, for the left and right plows 6 and 7 (conveyors 4 and 5), $\Delta \mathrm{H}_{\mathrm{pr} 6}$ and $\Delta \mathrm{H}_{\mathrm{pr} 7}$ indicated in the project of works implementation.

The deviation from the project values is calculated by the formulas (3) and (4):

$$
\begin{aligned}
& \delta_{6}=\Delta \mathrm{H}_{\mathrm{pr} 6}-\Delta \mathrm{H}_{6} \\
& \delta_{7}=\Delta \mathrm{H}_{\mathrm{pr} 7}-\Delta \mathrm{H}_{7}
\end{aligned}
$$

Cross slope of the cutting is calculated by the formula (5:)

$$
\mathrm{a}_{\mathrm{cs}}=\Delta \mathrm{H}_{6}-\Delta \mathrm{H}_{7} / \mathrm{B}^{*} \rho ”
$$

where $\alpha_{c s}-$ a cross slope of bar chain 8 ,

B - a bar chain length 8 ,

$\rho-206265$ - the number of seconds in radian.

The difference in the cutting depth corresponds to the excess of $h$ between antennas 9 , 10 and plows 6 and 7 , which is required in the implementation of this technical solution $\mathrm{h}=$ $\Delta \mathrm{H} 6-\Delta \mathrm{H} 7$.

The calculated data from the block 24 is being sent to the block 25 to control the depth of cutting ballast by plows 6,7 on the left and right conveyors 4,5 .

The control of the work on cutting the ballast layer with ballast cleaning machines is carried out in the dispatch center of the railroads repair units and is carried out using a specially developed program application using digital maps figure 5 [12].

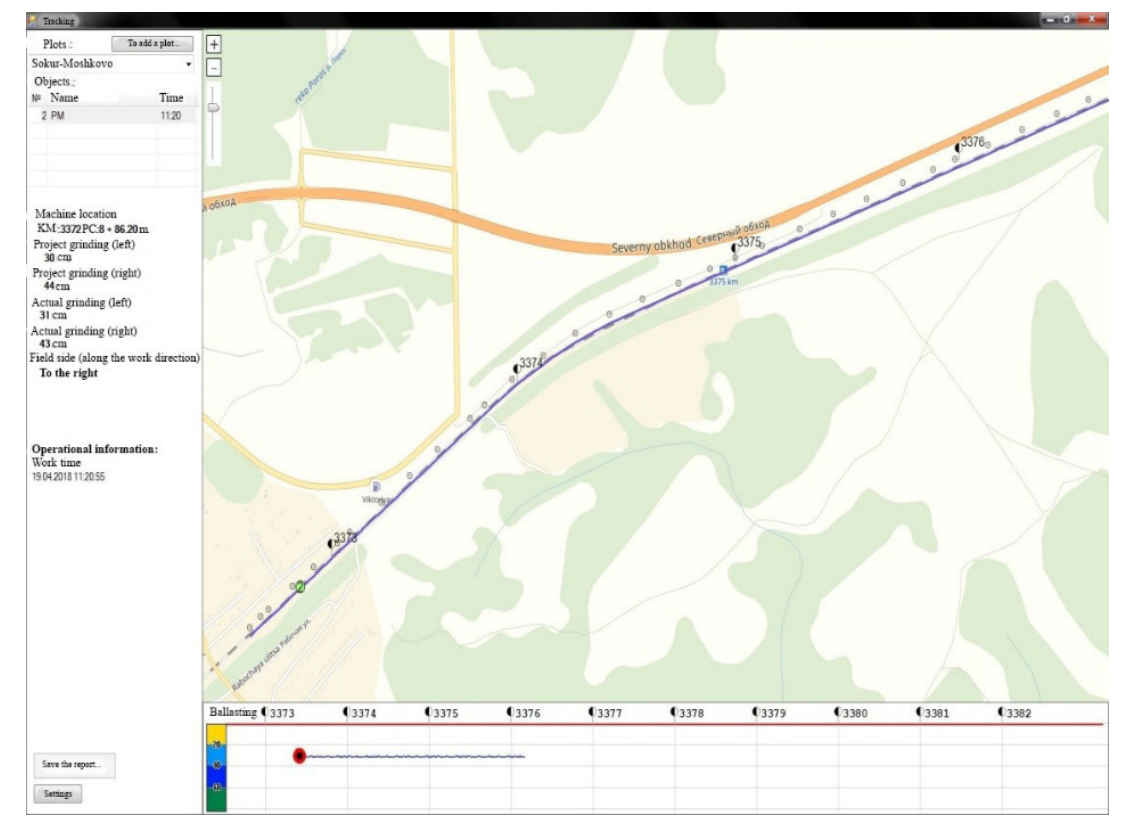

Fig. 7. Control of ballast cutting parameters by a ballast cleaner in the dispatch center. 


\section{Results and Discussion}

Thus, the rigid connection of the antennas 9 and 10 with the corresponding plows 6 and 7 and, respectively, with the bar chain 8 located at a depth of, for example, $50 \mathrm{~cm}$ below the rail head, makes it possible to control the movement of the bar chain 8 in a vertical plane along the height and transverse slope in a given range.

Satellite antennas 9 and 10 for receiving data from navigation satellites are above the frame 2 of the ballast cleaner 1 and the plows 6 and 7 and the bars circuit 8 are below the satellite antennas for $6 \mathrm{~m}$, it can be stated that the solution has allowed to solve the problem of controlling depth of cut and cleaning of the ballast on railways using GNSS.

The accuracy of determining the depth of cut of ballast and lateral slope due to the use of geodetic methods using GNSS technology meets regulatory requirements. This approach provides not only high accuracy, but also performance. The preparatory stage of shooting is excluded; the formation of the clipping project occurs immediately before the start of a major overhaul or reconstruction. Through the use of GIS technologies and digital models, constant visual control is provided, including in the dispatch center, and an executive survey is actually performed.

This technical solution is simple to use and has been used successfully on the WestSiberian Railway in the ballast cleaner machines.

\section{References}

1. Rules for the technical operation of the railways of the Russian Federation: TsRB-756. Minist. of Railw.of the RF of Dec. 21, 2010 No. 286. Transport, Moscow (2002)

2. Instructions for decoding tapes and assessing the condition of the rail gauge according to the testimony of the Central Research Institute-2 and measures to ensure the safety of train traffic. Minist. of Railw. of the R.F., CP-515 (1997)

3. A special reference system for monitoring the condition of the railway track in the profile and plan: technical requirements. VNIIZhT, Moscow (1998)

4. I.V. Shcherbakov, The hardware-software complex "Profile-M" for determining spatial and geometric parameters of the rail track. Vestnik SSUGiT 22(3), 60-71 (2017)

5. V.V Shcherbakov, A.I. Pimenov, I.A. Buntsev, I.V. Shcherbakov, O.V. Kovaleva, Development of automated track alignment control systems based on GNSS. Transport construction 9, 22-25 (2015)

6. O.V. Kovaleva, The use of GIS technology in determining the spatial position and geometric parameters of the railway. In: Interexpo GEO-Siberia-2013, 3. Geodesy, geoinform., cartography, surveying: Sat. internat. materials scie. Congr., 101-107. SGUGiT, Novosibirsk (2013)

7. V.V. Shcherbakov, A.N. Modestov, Pat. 126011 Russian Federation. IPC 51 E01B. Crushed stone cleaning machine. Appl. and pat. Hold. 2012124581 (2012)

8. V.V. Shcherbakov, A.I. Pimenov, I.A. Buntsev, I.V. Shcherbakov, Pat. 187173 of the Russian Federation IPC E01B27 / 10. Crushed stone cleaning machine Bul \# 10. Appl. 201828963/11 of 08/06/2018 (2018)

9. V.V. Shcherbakov, I.A. Buntsev, O.V. Kovaleva, I.V. Shcherbakov, A.I. Pimenov, Operational experience of automated track straightening systems at the Russian Railways Railways. In: Interexpo GEO-Siberia-2015. T. 2. Geodesy, geoinformatics, cartography, mine surveying: a collection of materials Intern. scientific Congr., 119124. SSUGiT. Novosibirsk (2015) 
10. O.V. Kovaleva, The experience of introducing satellite positioning equipment and automated control systems (ACS) developed on their basis in the construction and operation of railways. In: Political transport systems. Materials of the VIII Intem. Scie. and Tech. Conf. as part of the Russ.-EU Science Year, 247-253. Novosibirsk (2015)

11. A.M. Kulizhnikov, A.A. Anufriev, I.P. Kolesnikov, The regulatory framework for selfpropelled guns $3 D$. CAD and GIS of highways 2, 38-41 (2014)

12. V.V. Shcherbakov, O.V. Kovaleva, I.V. Shcherbakov, Digital track models - the basis of geodetic support for the design, construction (repair) and operation of railways. Geodesy and Cartography 3, 12-16 (2016) 